\title{
Three Genres of Sociology of KNOWledge And Their MarXist Origins
}

Tamás Demeter

\section{Summary}

In the present paper I sketch three genres of sociology of knowledge and trace their roots to Marx and Marxist literature while reconstructing two causal and one hermeneutic strand in this context. While so doing the main focus is set on György Lukács and György Márkus and their interpretation of Marx’s contribution to sociologically minded theories of knowledge. As a conclusion I point out that Marx-inspired sociologies of knowledge are more sensitive to the relation of larger-scale social and historical processes than to the actual practices of knowledge production, and that recent developments in science studies tend to integrate larger- and smaller-scale sociological sensitivities.

\section{Keywords}

sociology of knowledge, ideology-critique, hermeneutics, causation

\section{Introduction}

Marxist sociologies of knowledge are frequently represented in terms of the basesuperstructure dichotomy, i.e. as focusing on the economic determination of intellectual production and its contents. From the early critics on it has been typical to accuse Marxist approaches as relying on an impoverished model of the social embeddedness of intellectual production. Elizabeth Nemeth rightly expresses the consensus that Mannheim's and Scheler's sociologies of knowledge in the 1920s and '30s, and Merton's theories in the '40s and '50s were at least partly but crucially delimited against "Marxist social theory and its materialist thesis that being determines consciousness" (Nemeth 2008, 279). One could add that even those, like the young Lukács who converted to Marxism fairly soon, were initially inclined to criticize Marxism on the grounds that it stipulates an all too close and direct connection between the economic relations of 
production and the intellectual content produced in a given period. ${ }^{1}$

Frequently lurking behind these representations is the idea transparent in the young Lukács, namely that for Marxists the works of intellectual production can be exhaustively explained from their economic base. But if Marx's theory of ideology is given a more nuanced reading, then it becomes evident that the superstructure consists of institutions, not works. These institutions, such as schools, universities, media, courts etc., select and disseminate ideas that are suitable for ideological service in supporting the dominance of the ruling classes: the institutional environment in which ideas emerge and spread performs an almost evolutionary selection of the ideas.

However, the evolution of the institutions, or the ideological superstructure in general, ${ }^{2}$ is a function of the evolution of the productive forces which have an intrinsic tendency to evolve, and as such this process is beyond the control of the ruling classes. ${ }^{3}$ The connection between intellectual content and economic relations is mediated by institutions that are tools of social dominance and reflect existing power structures, but economic and social relations do not directly determine the intellectual content of particular works as such - the latter cannot be derived from the former.

My main intention here is to explore three perspectives that originated from a Marxist framework and taken together transcend the idea of the economic determination of intellectual production. Accordingly, I will reconstruct three possible Marxist or Marxinspired approaches and in this way suggest that even in its early development Marxist sociologies of knowledge made more complex contributions than their simplifying critiques would acknowledge. The three genres of Marxist sociology of knowledge to be introduced here suggest a rather complex outlook on the social history of ideas whose various strands can be seen as anticipating further developments in the field, developments that transcend the boundaries of Marxist traditions in social theory. In conclusion, however, I draw attention to the predominantly non-constructivist character of Marxist sociologies of knowledge that distinguishes them from accounts inspired by Wittgenstein, Polányi or Kuhn.

\footnotetext{
${ }^{1}$ I introduce Lukács's pre-Marxist sociology of knowledge in Demeter 2012.

${ }^{2}$ For a discussion see Bukharin 1925, $204 \mathrm{f}$.

${ }^{3}$ For a discussion see e.g. Rigby 1998, 43ff.
} 


\section{Speaking a Causal Idiom}

Perhaps the most familiar strand in Marxist sociology of knowledge is that which comes closest to the idea of the economic determination of the ideological superstructure. This strand is focused on the exploration of the causal processes linking social circumstances and intellectual production. This causal idiom is frequently expressed in various passages of The German Ideology and other writings, ${ }^{4}$ and it may be rightly considered as the most important focus of Marx's sociology of knowledge, especially when he deploys a critical approach to those forms of mental production that he considers ideological: "politics, laws, morality, religion, metaphysics etc." (Marx - Engels 1998, 42) The critical thrust in The German Ideology is, of course, mainly directed toward the Hegelian legacy of idealism in philosophy that proclaims the primacy of the spirit in history over the processes of the material world.

The strand of Marx's sociology of knowledge that speaks the causal idiom intends to replace this metaphysical image of ideas that "descends from heaven to earth" by grounding ideas in the processes of real life, thereby "ascending from earth to heaven" Less metaphorically, this aspiration is based on the insight that

Men are the producers of their conceptions, ideas, etc. - real, active men, as they are conditioned by a definite development of their productive forces and of the intercourse corresponding to these, up to its furthest forms. (Marx - Engels $1998,42)$

On this account productive forces are causes in the sense that they are part of a set of conditions that trigger the production of particular ideas: ${ }^{5}$ they are not necessary and sufficient in themselves as they do not guarantee the emergence of those particular ideas, but they are causes in the sense that intellectual production is "conditioned" by them.

\footnotetext{
${ }^{4}$ See also Marx 1955.

${ }^{5}$ Productive forces can be aptly understood as 'inus conditions' of intellectual production as John Mackie $(1965,245)$ defines them. Accordingly, a cause "insufficient but a necessary part of a condition which is itself unnecessary but sufficient for the result". This kind of causal talk is widespread in sociologies of knowledge that do not focus on productive forces, but other social factors such as traditions, customs, and socialization. A good example is the recent monumental study by David Bloor concerned with the early twentieth-century development of aerodynamics, which "explains the preconditions of success and failure" (Bloor 2011, 420).
} 
On this view, there is certainly a place for individual creativity, but it is constrained in at least two ways. Creativity, on the one hand, is inevitably exhibited in a specific institutional and social setting that provides the framework of socialization as a background for any kind of creative work. On the other hand, the emergence of ruling or successful ideas is due to a process of selection that is driven by the institutional superstructure. Thus, it is thus through institutions that economic relations exert causal influence on the production of ideas.

Although Marx was inclined to exempt science from ideological influences, ${ }^{6}$ an exemplary analysis of such conditioning can be found in Boris Hessen's 1931 classic study on the genesis of Newtonianism. ${ }^{7}$ Hessen's first thesis is the claim that a particular aspect of the productive forces in the early modern period, namely its machine technology, was a condition of the development of early modern mechanics, a thesis that is fairly explicitly confirmed in Newton's preface to the Principia where he claims that "mechanics is the subject that comprises all the manual arts." He goes even further when he claims that "geometry is founded on mechanical practice." It seems that Newton himself may be even more radical than Marx when he subsumes geometry, for Marx a non-ideological form of knowledge, to mechanical practice, i.e. to a given level of development of the productive forces. ${ }^{8}$

Hessen's second thesis strengthens the first and explains the lack of development in other fields of physics, such as, for example, thermodynamics, with recourse to the lack of existing technologies. Taken together, the two theses represent forces of production as inciting and limiting factors that as such determine knowledge production. Hessen's first two theses illustrate the direct causal link between the development of productive forces and intellectual production in general. ${ }^{9}$

In his History and Class Consciousness (1923) Georg Lukács drew attention to another set of conditions that explain the success of early modern mathematical natural philosophies, namely economic conditions and their formative influence on perceptions of nature and society. Lukács emphasizes the tendency of capitalism to produce a social structure that fits conveniently with the outlook of the modern mathematical natural

\footnotetext{
${ }^{6}$ For a discussion see Cohen 1978, 46, Lynch 1994, 199.

${ }^{7}$ It has been recently republished as Hessen 2009.

${ }^{8}$ Although the Preface is largely ignored by the interpreters of Newton, Guicciardini (2009, 293-299) offers an illuminating discussion of this aspect.

${ }^{9}$ For a good summary of Hessen's theses see Freudenthal and MacLaughlin (2009).
} 
sciences: due to the centrality of mathematical representation the natural sciences reduce phenomena to numerical relations. It belongs to the "essence of capitalism" as Lukács (1968a, 176) puts it, that it "produces" the phenomena this way: The capitalist mode of production brings with it the economic way of viewing things of which mathematical natural philosophy is a natural consequence: it represents and processes nature in categories that reflect the perception of life under conditions which reduce people to abstract quantities and mechanical ingredients of rationalized processes (Lukács 1968a, 349-350).

This is why and how medieval science gives way to modern science. The latter is distinguished by the following set of features: qualitatively homogeneous laws replace qualitative classification; immanent causal processes replace transcendent connections; numerical categories and relations as well as exact measurement take precedence (Lukács 1968a, 288-290). If seen through these categories, the order of nature and society both appear to be eternally fixed and immune to historical change, a representation that fits well the class interests of the bourgeoisie in conserving property relations and power structures. Due to their influence on the relevant institutions, ruling classes in general have the potential to "penetrate" [durchdringen] phenomena according to their own class interests (Lukács 1968a, 241). The rise of the bourgeoisie thus facilitates the proliferation and wide acceptance of the new science. ${ }^{10}$

The ability to penetrate phenomena entails that even fundamental categories such as 'nature', despite their representation as eternal categories in modern science and philosophy, are historically contingent. As Lukács (1968a, 410) puts it: „Nature is a historical category." And he clarifies the point as follows: what counts as nature, what this category means, what the relation of human beings to nature is, and how human beings are confronted with nature - the answers to these questions depend on social influences, because the content of 'nature' changes in response to the practical needs and experiences of those who put nature to theoretical use. In this way one could naturally conclude that the concept of 'nature', and arguably many more belonging to the same family, are socially constructed concepts.

Therefore, on Lukács's account the causal influence of social factors extends

\footnotetext{
${ }^{10}$ Much of subsequence history of science can be made out to be consistent with Lukács's overall picture. See for example Shapin 1981; Lawrence 1979.
} 
beyond the sphere of selection and dissemination of ideas capable of ideological service: social have a formative role to play in the emergence and development of methods and concepts in science. The way people perceive the categories and processes of social reality influences how they perceive reality in general. 'Nature' and other fundamental categories of understanding nature and society result from a dynamic historical process, and thus the knowledge one can gain of phenomena is inevitably prone to social and ideological influences.

\section{Social Hermeneutics}

Due to its Marxian origins, ideology-critique is frequently understood as a method for unmasking the interests lying behind ideas. This method relies on the particular concept of ideology (cf. Mannheim 1968, 57ff.), virtually a synonym of a lie that serving to justify the interests of a social class, for Marx typically those of the ruling class. Ideology is thus a form of social power (cf. Little 1991, 125-127): functionally, it serves the purpose of distorting the perception of reality within class society. The means of this distortion are cultural institutions such as schools, churches, works of art, and traditions that present particular interests as general interests. They thereby facilitate the maintenance of social relations that correspond to the particular interests of the ruling classes. As a result, ideology masks social injustices and makes them tolerable to the exploited, in this way deterring them from a rational, in particular revolutionary, course of action. The purpose of ideology-critique in this sense is to offer a critique of social relations by unmasking these distortions.

Approaching ideas with this unmasking attitude results in reductionism: the content of ideas is reduced to sociologically specified circumstances within which agents put them forward or represent them. As with the sociology of knowledge, ideologycritique for the purpose of unmasking is a causal outlook: the individuals' positions in the productive processes constrains the perspective from which they can put ideas forward. The difference between the sociology of knowledge and unmasking is that the latter considers the relations of social production to be fundamentally decisive with regard to meaning, while the sociology of knowledge builds upon a more general and broader base 
with the intention of deriving theoretical interconnections from extra-theoretical constellations (cf. Mannheim 1982, 82).

Due to this narrower scope, unmasking does not move beyond the conceptual resources provided by the dichotomy of the economic base and institutional superstructure. Ideology-critique unmasks the real functioning of the cultural superstructure by reducing the meaning of cultural production to its practical base. Up to this point ideology-critique goes hand in hand with sociology of knowledge as far as focusing on causal relations is concerned.

Unmasking faces several difficulties. It strictly separates science and ideology: it portrays the former as aiming at an undistorted picture of reality - it pictures science as aiming at truth, not at masking reality. Given this distinction, ideology-critique itself is taken to be a kind of science (cf. Márkus 1995, 91), social science, and it is thus close to the sociology of knowledge in this respect too. But this similarity results in a feature alien to the principles of the sociology of knowledge: by classifying ideology-critique as science, ideology-critique as unmasking denies the need for reflexivity, the fourth principle in the strong program's methodology. This is because the unmasking ideology-critique is connected to a nineteenth-century view of science (cf. Cohen 1978, 46; Lynch 1994, 199), which is, following Kuhn, Bloor, and others, no longer tenable. Furthermore the unmasking ideology-critique can serve and, in The German Ideology does serve, ideological purposes by its own standards. All this shows that ideology-critique is in need of revision, and in the unmasking sense it cannot be applied as a method of interpretation in the history of ideas - only as a tool for political activists.

Traces of an alternative concept already appear in Marx (cf. Márkus 1995), providing the possibility of overcoming the problems of the orthodox Marxist conception. The greatest shortcoming of the unmasking ideology-critique is that it overlooks the evaluative aspects of the term 'culture' while emphasizing exclusively the masking and justificatory functions of its content. Thus, it also ignores the possibility that cultural production may not necessarily be a means of upholding the social power of the ruling classes, as other authors such as William Lynch $(1994,198)$ and Daniel Little (1991, 130) think, but the expression of the most sophisticated human capacities (cf. Cohen 1978, 205). Ideologies also give creative, socially motivated answers to problems arising from life situations that are related to the inherited cultural canon. If viewed from 
this angle, an alternative, emancipatory concept of ideology is in order that emancipates, as it were, the concept from its exclusively negative, distorting connotations (Márkus 1995 $68,72)$.

Ideology-critique based on the emancipatory notion of ideology is a hermeneutic, and not a political, enterprise. Hermeneutics is based on a commitment to reveal how various social practices are reflected in the realm of ideas, and "[i]n this sense ideologycritique is the transposition of the traditional method of immanent criticism from the realm of the textual into that of the social." (Márkus 1995, 72) It aims at revealing how unreflexive presuppositions, the limits and structure of discourse and representation, as well as conceptual schemes reflect social circumstances.

Emancipatory ideology-critique reveals the social relevance of ideological forms of knowledge, or to put it more precisely it reveals the significance of ideas in relation to a given social-historical situation. This may result in revealing unintended meanings. In specific social contexts certain intellectual works may be interpreted independently of, or even contrary to, the intentions of their authors. Interpretations developed in this way can, of course, be divergent in several ways. There is no uniquely correct reading for example, nor quasi-scientific explanation, and even more significant, there are no criteria for judging the correctness of interpretation. The outcome of the interpretation depends on the particular aspects of the social context on which emphasis is placed in the process of reconstruction. Accordingly, there are several levels of sociologically relevant meaning that can be revealed with this method.

Correspondingly, the idea of the functional and/or causal determination of thought becomes irrelevant from this point of view, as it is replaced by the idea that the meaning of particular works can be understood as reflecting social relations - and this meaning can be accessed via ideology-critique. The emancipatory ideology-critique does not necessarily consider ideas as being determined by economic, social, historical or other circumstances, thus it can accommodate the fact that reflection can take several, even divergent forms of expression (cf. Márkus 68, 73). It does not presuppose either that ideology belongs exclusively to the ruling classes - although they might be better placed to spread their own (cf. Cohen 1978, 291).

Thus the method of ideology-critique, as both Cohen (e.g. 1978, 216) and Márkus $(1995,73)$ emphasize, can overcome the dichotomy of economic base and 
ideological superstructure. Cohen $(1978,46)$ also points out that the interpretation of ideologies within the framework of this dichotomy is problematic from the beginning, as by definition the superstructure consists of institutions, and the works of culture are not themselves institutions but ideas. Similarly, emancipatory ideology-critique does not primarily deal with culture as an institutional structure, even if cultural institutions themselves play their part in cultural production. If viewed from this perspective, economic relations or, to use a more general term, the practical base, do not cause the content of ideas, but provide an angle for interpretation, a point of view from which a meaningful work can be understood in the context of the chain of events in the economy, society, history and so on. What is then important is not the social genesis of ideas, but their meaning and significance in a given context.

As we have seen above, the particular concept of ideology fits fairly well with the method of the unmasking ideology-critique. The method of emancipatory ideologycritique is closer to the "total concept of ideology" - as Mannheim $(1968,57 \mathrm{ff}$.$) puts it,$ the "total structure of consciousness" of a given age or group - or, perhaps a better term, a worldview. In this sense Cohen's concept of an "ideological service” can be understood as being based on the ability to conceptualize and represent a worldview in a socially effective way.

Social Wirkungsgeschichte

The idea of the social efficacy of intellectual production brings us to the third genre of Marxist sociology of knowledge. At the very beginning of History and Class Consciousness Lukács (1968a, 171) quotes from Marx's Critique of Hegel's Philosophy of Law: "theory becomes a material force when it grips the masses." 11 This dictum clearly states that under certain social conditions ideas are not mere epiphenomena of social processes as the base-superstructure dichotomy suggests, but can function directly as productive forces. This suggest a mutual dependence between ideas and social circumstances: we have seen above that sociological factors can play a limiting and inspiring, i.e. causal role

\footnotetext{
11 See translation in Lukács 1968b, 2.
} 
in the process of intellectual production, but a similar role can be ascribed to ideas in the development of productive forces.

Ideologies, for example, can function as organizing principles of societies, as guides for setting up institutions and regulate social and everyday activities in general. Ideologies influence the way in which people create the sphere of potential actions and the system of rewards and punishments attached to it, and thereby form the perception of individual interest in a given social setting. The roots of this insight reach at least to the social and political theory of the Scottish Enlightenment. As David Hume puts it, it is "on opinion only that government is founded," and this "opinion is of two kinds, to wit, opinion of interest, and opinion of right" (1741a, 32-3). In order for a political entity to have a stable government, its subjects must believe that the government serves the public interest, and that it has the right to govern. Therefore the primary task of a "science of politics" is to explain how these opinions are formed and transformed.

For Hume, whatever the principles are that political actors express and adopt in political action, they are just disguised interests, i.e. ideologies. But interest has a much broader meaning than economic utility, because "though men be much governed by interest; yet even interest itself, and all human affairs, are entirely governed by opinion" (Hume 1741b, 51). So interests depend on the "opinion" of political actors, i.e. on what they think about their place in the world - about the social, natural, and even transcendent world around them.

The best-known and highly elaborated historical example of a similar social efficacy of ideology is probably Max Weber's account of the economic consequences of Protestantism and Merton's extension of Weber's insights to the genesis of modern science. Weber (1930) uncovers a unique worldview sustaining the emergence of capitalism. He explores various manifestations of this worldview from a rich variety of historical sources, and explains their psychological background in several categories like "fear of damnation," "inner isolation," and "inner-worldly asceticism" arising out of restraint from a culture of sensations, a sense of vocation, and a sense of duty etc. This psychology provides the conceptual framework by which members of Calvinist and similar communities made sense of their own and their fellows' behaviour, by which they admired or condemned it. It could thus function as an ideology that represented reality through categories that facilitated certain ways of behaviour and forbade others. 
Psychological categories like those above configured the agents' sensibilities, oriented them with respect to their courses of behaviour, social situations, and their sense of themselves etc., and hence motivated their social and economic behaviour. If Weber's reconstruction is accepted, then it is plausible to think that understanding agents under these categories was a driving force in early modern social history - independently of the question whether this "Calvinist psychology" is a true description of some real cognitive architecture or a distortion. What really matters is that in these communities these concepts provided the ways of motivating behaviour: members of communities could relate to the world and to one another through these concepts, and this understanding was motivationally relevant. The Calvinist ideology proved to be a "material force" when it gripped the masses.

It may not be surprising that it is easier to find classic elaborations of this idea outside the canon of Marxist literature than within it. One reason for the relative neglect of this approach may be methodological: prima facie this outlook conflicts with historical materialism, because it seems to violate the principle that the ultimate driving force in history is to be sought among the productive forces of society, and inflating the concept of a 'material force' to the extent that it includes ideas may seem to threaten the distinctive methodological stance of Marxism.

On second thought, however, including ideas or ideologies among productive forces may not be threatening at all. The development of productive forces and the production of ideas can be seen as largely independent processes which can have significant encounters. Some of these ideas are turned into ideologies the emergence of which can be seen, as G.A. Cohen $(1978,291)$ suggests, in a Darwinian, evolutionary way: "thought-systems are produced in comparative independence from social constraint, but persist and gain social life following a filtration process which selects those well adapted for ideological service." Ideas, just like mutations in the natural world, emerge, and depending on the social circumstances, are sometimes selected for ideological service. The role of these ideologies is, e.g., to paint the existing structures of social power in more fanciful colours, thereby disguising them and making them acceptable to those exploited by these structures. Until effective, ideas selected for such ideological service can indeed play the role of a productive force by e.g. maintaining social peace. 
In other cases ideas can play a more conspicuous role as Weber's insights suggest. The case of Protestantism can be interpreted as the story of an idea that emerges in a way that can be put in a causal framework, and the story can be narrated in sociological terms of previous unsuccessful heretic movements, the institutions of the Catholic Church, the crisis of the Catholic Church, and the social consequences of printing technology etc. And this story can be complemented with another in terms of the behaviour required by the then-contemporary development of productive forces in order to be more productive. It is not only the development of productive forces, but also the attitude of economic agents toward them that together explain further social developments. In Weber's case the widespread acceptance of the Protestant worldview and man's place in it lead to the emergence of the capitalist mode of production, and thus Protestantism turned out to be a productive force due to its influence on the masses. Arguably, technological development requires ideological support in order to reach the maximum of productive efficacy.

\section{Conclusion}

Above I sketched three perspectives from which the history of ideas can be looked at from a sociological perspective and showed that the roots of all three approaches can be traced back to Marx. Two of the three perspectives are interested in causal accounts: the first, perhaps classical, approach focuses on the influence of social and technological circumstances on the production of ideas; the third is focused on the social efficacy of ideas. The second approach sketched above is hermeneutic: it is not interested in causes and effects, but in a contextual understanding of meaning, where context is provided by sociological factors.

It is hard to overlook that, while drawing methodological boundaries between these sociologically oriented approaches to the history of ideas, the boundaries cannot be drawn sharply. The three approaches can be taken more or less simultaneously, or can be changed within a single study: it is easy to move back and forth between the focuses on the social determination of ideas and their social-historical meaning and significance 
from which their social efficacy follows. It also happens that the three approaches are intertwined to the extent that they cannot be visibly separated.

There is, however, one perspective to which sociological accounts inspired by Marx are not especially sensitive. Maybe due to the influence of Marx's philosophy of history, these sociologies of knowledge are more attracted to the project of connecting important episodes of intellectual history to large-scale processes of historical development and pay much less attention to the actual practices and social dynamics of scholarly communities. This sensitivity has been brought to the attention of science studies thanks to the influence of Wittgenstein, Polányi, and Kuhn who emphasized the process of socialization in scholarly and scientific communities. This process takes place in classrooms and laboratory training while transferring textbook science as well as tacit knowledge whose elements are not and cannot be laid down in textbooks. These microsocial processes transfer practices that are essential in knowledge production - and intellectual production in general.

Much of the later development of science studies is characterized by a growing consciousness that sociology of knowledge can be fruitfully integrated with these smallerscale accounts. For example, this consciousness seems to be characteristic of the recent development of the "strong program's" methodology in the sociology of knowledge. ${ }^{12}$ This fact indicates that a crucial feature of sociological accounts and a key to their plausibility lies in their methodological complexity. As ideas develop and exert their influence in a complex network of social and intellectual influences, the more complex a sociological interpretation is, the more plausible is the picture it can provide about the sociologically accessible aspect of ideas. Increasing the complexity of interpretation is then a sober heuristic rule to follow that should also be reflected in our methodologies as we strive toward an unified theory of interpretation for a social history of ideas.

\section{References}

Bloor, D. (2011). The Enigma of the Aerofoil: Rival Theories in Aerodynamics, 1909-1930. Chicago: University of Chicago Press.

\footnotetext{
${ }^{12}$ An excellent example of integration is Bloor 2011. For theoretical conclusions see especially chapter 10.
} 
Bukharin, N. (1925). Historical Materialism: A System of Sociology. New York: International Publishers.

Cohen, G.A. (1979). Karl Marx's Theory of History. Oxford: Clarendon.

Freudenthal, G. \& McLaughlin, P. (2009). Classical Marxist Historiography of Science: The Hessen-Grossmann Thesis. In G. Freudenthal \& P. McLaughlin (Eds.), The Social and Economic Roots of the Scientific Revolution: Texts by Boris Hessen and Henryk Grossmann. Dordrecht: Springer.

Guicciardini, N. (2009) Isaac Newton on Mathematical Certainty and Method.

Cambridge, Mass.: MIT Press.

Hessen, B. (2009). The Social and Economic Roots of Newton's Principia. In G.

Freudenthal \& P. McLaughlin (Eds.), The Social and Economic Roots of the Scientific

Revolution: Texts by Boris Hessen and Henryk Grossmann. Dordrecht: Springer.

Hume, D. (1741a). Of the First Principles of Government. In Essays Moral, Political, and Literary. Indianapolis: Liberty Fund, rev. ed., 1987.

Hume, D. (1741b). Whether the British Government inclines more to Absolute

Monarchy, or to a Republic. In Essays Moral, Political, and Literary. Indianapolis: Liberty

Fund, rev. ed., 1987.

Lawrence C. (1979). The Nervous System ad Society in the Scottish Enlightenment. In

B. Barnes \& S. Shapin (Eds.), Natural Order: Historical Studies of Scientific Culture.

London: Routledge.

Little, D. (1991). Varieties of Social Explanation: An Introduction to the Philosophy of

Social Science. Boulder: Westview.

Lukács, G. (1968a). Geschichte und Klassenbewusstsein. Darmstad - Neuwied:

Luchterhand.

Lukács, G. (1968b). History and Class Consciousness. Cambridge: Mass.: MIT Press.

Lynch, W.T. (1994). Ideology and the Sociology of Scientific Knowledge. Social Studies of Science, 24, 197-227.

Mackie, J.L. (1965). Causes and Conditions. American Philosophical Quarterly, 2, 245265.

Mannheim, K. (1968). Ideology and Utopia. London: Routldege \& Kegan Paul.

Mannheim, K. (1982). Structures of Thinking. London: Routledge \& Kegan Paul.

Marx, K. (1955). The Poverty of Philosophy. Moscow: Progress Publishers. 
Marx, K. \& Engels, F. (1998). The German Ideology. New York: Prometheus Books. Márkus, G. (1995). On Ideology-Critique - Critically. Thesis Eleven, 43, 66-99.

Nemeth, E. (2008). Logical Empiricism and the History and Sociology of Science. In Alan Richardson \& Thomas Uebel (Eds.), The Cambridge Companion to Logical Empiricism. Cambridge: Cambridge University Press.

Rigby, S.H. (1998). Marx and History. Manchester: Manchester Uuniversity Press. Shapin, S. (1981). Of Gods and Kings: Natural Philosophy and Politics in the LeibnizClark Disputes. Isis, 72, 187-215. 